\title{
REFERENCE
}

Simultaneous Visual and Calorimetric

Measurements of R11, R123, and R123/

Alkylbenzene Nucleate Flow Boiling

Mark A. Kedzierski

Building and Fire Research Laboratory

Gaithersburg, Maryland 20899

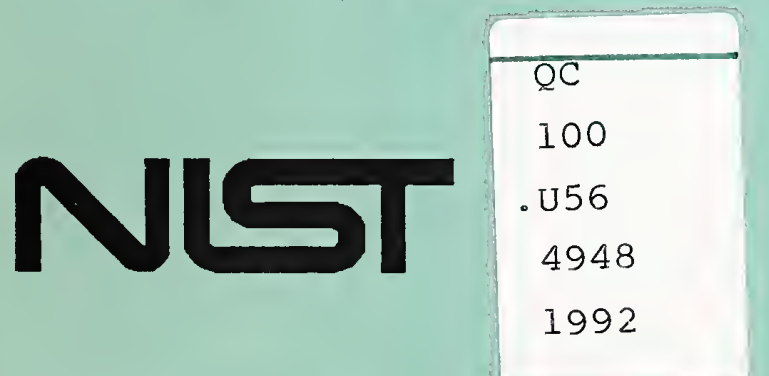

United States Department of Commerce

Technology Administration

National Institute of Standards and Technology 



\section{Simultaneous Visual and Calorimetric Measurements of R11, R123, and R123/ Alkylbenzene Nucleate Flow Boiling}

Mark A. Kedzierski

October 1992

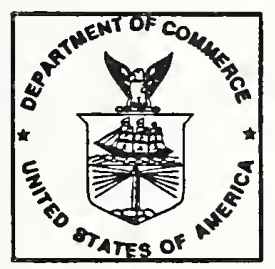

U.S. Department of Commerce Barbara Hackman Franklin, Secretary Technology Administration Robert M. White, Under Secretary for Technology National Institute of Standards \& Technology John w. Lyons, Director
Prepared for:

U.S. Department of Energy Office of Building Technology Building Equipment Division Conservation and Renewable Energy 1000 Independence Ave., SW Washington, DC 20585 



\begin{abstract}
Bubble formation during horizontal flow boiling of trichlorofluoromethane (R11), 1,1dichloro-2,2,2-trifluoroethane (R123) and two R123/alkylbenzene lubricant mixtures was investigated both visually and calorimetrically. The test fluid was pumped through the inside of a roughened, horizontal, quartz tube which was electrically heated with a metal strip. The refrigerant entered the test section with a quality slightly above the saturated state. Locally measured heat transfer coefficients were taken simultaneously with high speed motion picture images of the boiling process. Predictive equations from the literature yielded acceptable agreement with the measured bubble diameters and contact angles. The addition of lubricant to the R123 increased the size of the contact angle and reduced the size of the bubble. The agreement between existing correlations and the measured bubble frequencies and site densities was within the uncertainty of the measurements. The addition of a small amount $(0.5 \%)$ of alkylbenzene to R123 increases the number of active nucleation sites by approximately 5 sites $/ \mathrm{cm}^{2}$ which corresponds to a $12 \%$ to $50 \%$ increase in the site density. The increase in the site density contributed to the enhancement of the heat transfer coefficient of the R123/0.5\% alkylbenzene mixture over that of the pure R123. Further increase in the amount of alkylbenzene to the R123 reduces the number of active sites to below that of pure R123 to approximately the value for that of R11. Consequently, the $0.5 \%$ lubricant mass fraction mixture exhibited a heat transfer coefficient that was larger than that of the $2 \%$ lubricant mass fraction mixture. Correspondingly, the lower heat transfer coefficient of R11 as compared to that of R123 was partially due to the lower number of active boiling sites for R11. The dependency of the measured two-phase heat transfer coefficient on the heat flux and Reynolds number was investigated. Increases in both the heat flux and the Reynolds number caused increases in the heat transfer coefficient. The heat flux has a much larger effect on the heat transfer coefficient than the Reynolds number.
\end{abstract}




\section{ACKNOWLEDGEMENTS}

This work was funded jointly by NIST and the U.S. Department of Energy, Conservation and Renewable Energy, (project no. DE-AI01-91CE23808) under Project Manager Terry G. Statt. The author would like to thank the following personnel of NIST for their valuable inputs toward the completion of this work: Mr. J. Crowder, Mr. M. Kaul, Mr. R. Smith, Mr. D. Hahn, Dr. D. Ripple, Dr. J. Parise, Dr. M. McLinden, Dr. G. Morrison and Mrs. J. Land. The author would also like to express his appreciation to S. Olund of Chevron for providing the ZEROL Refrigeration Fluid 300 which was used as the test lubricant. 


\section{TABLE OF CONTENTS}

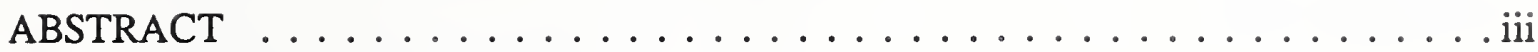

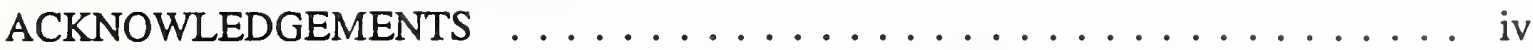

NOMENCLATURE $\ldots \ldots \ldots \ldots \ldots \ldots \ldots \ldots \ldots \ldots$

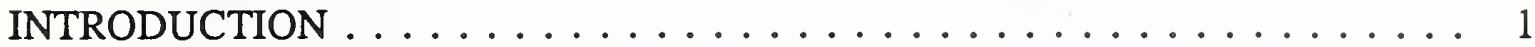

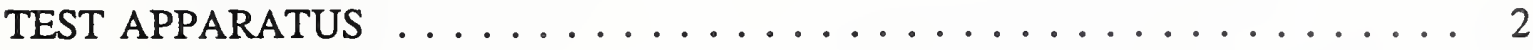

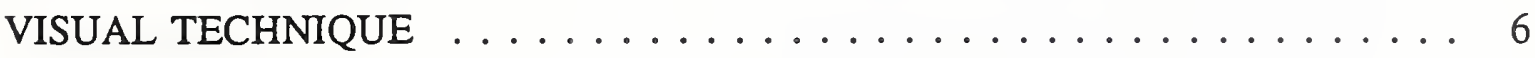

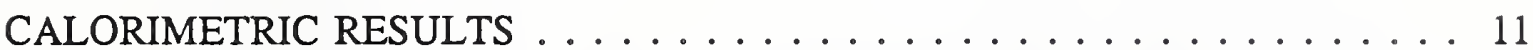

Pure R11 and Pure $123 \ldots \ldots \ldots \ldots \ldots \ldots \ldots$

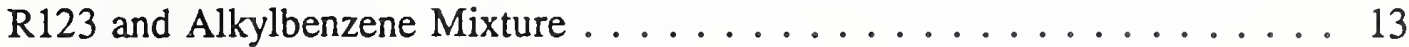

Correlation of Heat Transfer Coefficient ............... 16

VISUAL RESULTS . . . . . . . . . . . . . . . . . . . 18

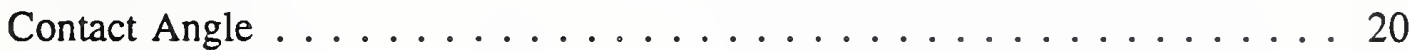

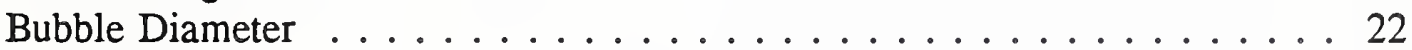

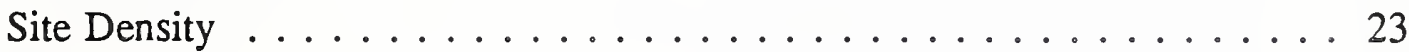

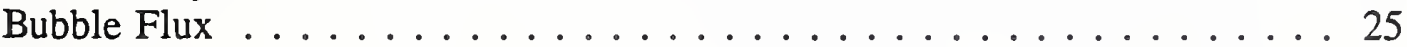

MECHANISTIC INTERPRETATION OF $\mathrm{h}_{2 \phi} \ldots \ldots \ldots \ldots \ldots$

CONCLUSIONS ............................. 28

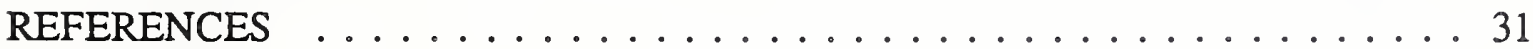

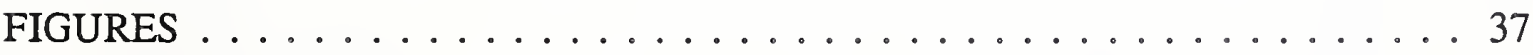




\section{NOMENCLATURE}

\section{English symbols}

A cross sectional surface area of bubble (m)

a major radius of bubble $(\mathrm{m})$

B constant in eqn. 19

b minor radius of bubble (m)

$\mathrm{C}_{\mathrm{n}}$ constant in eqn. 19

$c_{p} \quad$ specific heat $(\mathrm{J} / \mathrm{kg} \cdot \mathrm{K})$

$\mathrm{D}_{\mathrm{d}}$ bubble (departure) diameter $(\mathrm{m})$

$\mathrm{D}_{\mathrm{n}}$ constant in eqn. 19

$\mathrm{D}_{\mathrm{i}} \quad$ Internal diameter of quartz tube $(\mathrm{m})$

$D_{s} \quad$ equivalent spherical diameter $(m)$

$\mathrm{E}$ boiling constant in eqn. 15

f bubble frequency (bubbles/s)

$\mathrm{f}^{\prime \prime} \quad$ bubble frequency flux (bubbles $/ \mathrm{m}^{2} \mathrm{~s}$ )

fps film speed (frames/s)

g gravitational acceleration $\left(\mathrm{m} / \mathrm{s}^{2}\right)$

$\mathrm{H}_{\mathrm{i}} \quad$ radial height of image of bubble (m)

$\mathrm{H}_{\mathrm{o}} \quad$ radial height of bubble object $(\mathrm{m})$

$\mathrm{h}_{2 \phi}$ two-phase heat transfer coefficient $\left(\mathrm{W} / \mathrm{m}^{2} \cdot \mathrm{K}\right)$

$\mathrm{h}_{\mathrm{fg}} \quad$ latent heat of vaporization $(\mathrm{J} / \mathrm{kg})$

I constants in optical correction eqn. $\left(\mathrm{m}^{2}\right)$

$\mathrm{K}_{\mathrm{p}} \quad$ dimensionless pressure, see eqn. 16

$\mathrm{k}$ thermal conductivity $(\mathrm{W} / \mathrm{m} \cdot \mathrm{K})$

m mass flow rate $(\mathrm{kg} / \mathrm{s})$

$\mathrm{N}_{\mathrm{e}}$ number of end-bubbles for one trace

$\mathrm{N}_{\mathrm{f}} \quad$ number of filming frames

$\mathrm{N}_{\mathrm{z}}$ number of zero-bubbles for one trace

$\mathrm{n} \quad$ site density $\left(\right.$ sites $\left./ \mathrm{m}^{2}\right)$

$\mathrm{P}$ pressure $(\mathrm{Pa})$

Pe Peclet number, see eqn. 17

$\mathrm{P}_{\mathrm{c}} \quad$ critical pressure $(\mathrm{Pa})$

$\mathrm{P}_{\mathrm{r}} \quad$ reduced pressure $=\mathrm{P}_{\mathrm{s}} / \mathrm{P}_{\mathrm{c}}$

$\mathrm{P}_{\mathrm{s}} \quad$ saturation pressure $(\mathrm{Pa})$

$\mathrm{q}_{\mathrm{g}} \quad$ heat transfer due to bubble generation (W)

$\mathrm{q}_{\mathrm{n}} \quad$ nucleate heat transfer (bubble generation \& sensible) (W)

q" heat flux $\left(\mathrm{W} / \mathrm{m}^{2}\right)$

$\mathrm{q}_{\mathrm{n}}$ nucleative heat flux $\left(\mathrm{W} / \mathrm{m}^{2}\right)$

$\operatorname{Re} \quad$ Reynolds number $=4 \dot{\mathrm{m}} / \mu_{1} \cdot \pi \cdot \mathrm{D}_{\mathrm{i}}$

$\mathrm{R}_{\mathrm{a}} \quad$ mean surface roughness (m)

$R_{p} \quad$ Glättungstiefe or peak-to-mean surface roughness (m)

$\mathrm{R}_{\mathrm{q}} \quad$ rms surface roughness (m) 
r radial tube coordinate with origin at tube center $(\mathrm{m})$

$\mathrm{s}_{\mathrm{f}} \quad$ standard deviation of measured bubble frequency $\left(\mathrm{s}^{-1}\right)$

$s_{\beta} \quad$ standard deviation of measured $\beta$ (deg.)

$\mathrm{T}_{s} \quad$ saturation temperature $(\mathrm{K})$

$\mathrm{T}_{\text {wi }}$ temperature of the internal tube wall (K)

$t$ time (s)

$V_{o} \quad$ actual or object volume of bubble $\left(\mathrm{m}^{3}\right)$

$V_{e} \quad$ volume of all the end-bubbles for one film-trace $\left(\mathrm{m}^{3}\right)$

$V_{z} \quad$ volume of all the zero-bubbles for one film-trace $\left(\mathrm{m}^{3}\right)$

$\mathrm{W}$ mass fraction of lubricant in mixture

$\mathrm{x}$ axial tube coordinate $(\mathrm{m})$

Greek symbols

$\beta \quad$ dynamic contact angle (deg.)

$\Delta \mathrm{T}_{\mathrm{s}} \quad \mathrm{T}_{\mathrm{s}}-\mathrm{T}_{\mathrm{wi}}(\mathrm{K})$

$\Delta \mathrm{t} \quad$ time difference between zero and end time lines (s)

$\theta$ angle between bubble major axis and $\mathrm{r}$ (deg.)

$\mu \quad$ dynamic viscosity $(\mathrm{kg} / \mathrm{m} \cdot \mathrm{s})$

$\nu \quad$ kinematic viscosity $\left(\mathrm{m}^{2} / \mathrm{s}\right)$

$\rho$ density $\left(\mathrm{kg} / \mathrm{m}^{3}\right)$

$\sigma \quad$ surface-tension $(\mathrm{N} / \mathrm{m})$

\section{Subscripts}

b bubble

e end

i image, inner tube surface

L lubricant

1 liquid

m mixture

o object

r pure refrigerant

$s \quad$ saturation

v vapor 



\section{INTRODUCTION}

This paper presents a comparison of calorimetric and visual measurements of horizontal nucleate flow boiling of four fluids: (1) trichlorofluoromethane (R11), (2) its proposed replacement, the alternative refrigerant 1,1-dichloro-2,2,2-trifluoroethane (R123), (3) a R123/0.5\% weight alkylbenzene lubricant mixture, and (4) a R123/2\% weight alkylbenzene lubricant mixture; the nominal kinematic viscosity of the lubricant was 53 $\mu \mathrm{m}^{2} / \mathrm{s}$ (280 SUS) at $313.15 \mathrm{~K}$. The calorimetric aspect of this study focuses on the measurement of the local two-phase heat transfer coefficient $\left(h_{2 \phi}\right)$. The visual measurements obtained from high-speed $16 \mathrm{~mm}$ film of the boiling were taken simultaneously with the calorimetric measurements. The bubble diameters $\left(D_{d}\right)$, the bubble frequency flux ( $\left.f^{\prime \prime}\right)$, the site density $(\mathrm{n})$ and the contact angle $(\beta)$ were derived from over 40 high-speed films containing approximately 3000 bubbles.

Visual observation of the ebullition process is an excellent method by which knowledge of the fundamental mechanisms of boiling can be obtained. Currently, the heat transfer cannot be predicted a priori with a general mechanistic model. In order to establish the foundation for this goal, fundamental mechanisms must be observed and correlated for use in such a model. Rohsenow (1988) has brought to our attention the need for better correlations for the bubble diameters, the bubble frequency (f), and the site density. He cited the Mikic-Rohsenow (1969) model which partitions the total heat flux between that used to generate the bubbles and that convected from the surface. Someday, fundamental 
and generic mechanistic boiling information will be used to accurately design and optimize refrigeration equipment. This paper adds to the available mechanistic boiling data and examines the applicability of several existing correlations to predict mechanistic information.

\section{TEST APPARATUS}

Following is a discussion of the test apparatus and the accuracies associated with the individual measurements. Unless otherwise stated, all accuracies are estimated for a $99.7 \%$ confidence interval.

A schematic of the test apparatus is shown in Fig. 1 to illustrate the circulation of refrigerant through the individual components of the rig. A hermetic, oil-free pump was used to deliver a constant flow rate throughout the test rig. The test fluid entered the fluid heater subcooled and exited in a two-phase state at near $1 \%$ vapor quality. The electric heater was used to achieve higher flow qualities entering the test section. After exiting the test section, the fluid entered a liquid reservoir which served to condense the vapor produced by the quartz tube and the fluid heaters and to establish and maintain a steady system pressure. The liquid exiting the condenser was subcooled by approximately $40 \mathrm{~K}$ and entered the mass flow rate meter. The refrigerant mass flow rate (m) was measured with a coriolis flow meter with an accuracy of $1-2 \%$ of the measured value. The test loop was completed by returning the liquid to the pump. 
The test section consisted of a $9 \mathrm{~mm}$ internal diameter quartz tube with a $3 \mathrm{~mm}$ wall thickness. A thin $(0.25 \mathrm{~mm}), 3 \mathrm{~mm}$ wide brass strip was located horizontally along the bottom of the tube with its length aligned with the flow direction. A direct current was passed through the brass strip to produce a range of uniform heat fluxes (q") from 15 to $30 \mathrm{~kW} / \mathrm{m}^{2}$. The quartz tube was enclosed in a safety housing with four flat windows located at opposite poles for lighting and filming of the boiling. The space between the housing and the quartz tube was evacuated in order to minimize the heat loss from the heater strip to the surroundings and, thus, promote one-dimensional conduction into the tube. The all-liquid Reynolds numbers based on the diameter of the quartz tube ranged from 0.0 to 9,500 . The accuracy of the Reynolds number was $1.4-2.2 \%$ of the calculated value. The measurements for all fluids were obtained from the same smooth-tube test rig to ensure that observed differences were due to the characteristics of the fluids.

The inside surface of the quartz tube was roughened with a five micron polish to promote boiling. The roughness of the tube was measured, using a stylus instrument. The root mean square (rms) roughness $\left(R_{q}\right)$, the Glättungstiefe (peak-to-mean) roughness $\left(R_{p}\right)$, and the average roughness $\left(R_{a}\right)$ of the interior quartz surface were approximately $0.36 \mu \mathrm{m}, 1$ $\mu \mathrm{m}$, and $0.3 \mu \mathrm{m}$, respectively. The $\mathrm{R}_{\mathrm{a}}$ measurement is a good indication of the depth of the average cavity. Close examination of the roughness trace reveals inclusions of approximately 1 micron in width. Presumably, the average cavity is approximately 1 micron wide at the mouth and approximately 0.3 microns deep. 
Care must be taken in the instrumentation of a quartz test specimen to accurately measure the heat flux. The main concern is determining what portion of the energy generated in the brass heater strip actually gets into the tube. Figure 2 shows the instrumentation of the quartz tube with a heater composite which was used to measure the heat transfer coefficient. The heater composite was made by cementing two thermocouples to the center of opposing sides of a plastic strip of known thermal conductivity. The thermocouple nearest the tube was approximately $0.5 \mathrm{~mm}$ in diameter and flush with the surface of the plastic. The $5 \mathrm{~mm} \times 3 \mathrm{~mm} \times 76 \mathrm{~mm}$ long plastic strip was cemented to a thin $(0.25 \mathrm{~mm})$ brass strip of equal width and length. The entire heater assembly was then cemented to the bottom of the quartz tube. The purpose of the assembly was, first, to direct most of the heat flux into the quartz tube, and, second, to provide for a method to calculate the amount of heat that enters the tube.

The heat flux incident to the quartz tube (q") and the temperature of the inner tube wall $\left(\mathrm{T}_{\text {wi }}\right)$ were determined from both measurement and theory. For example, the twodimensional conduction within the plastic strip was modeled in order to determine the amount of energy transferred to the surroundings from the sides and bottom of the insulating strip. The model predicted a linear heat loss with respect to the temperature difference across the plastic. Consequently, the heat loss from the sides and bottom of the plastic was calculated from the measured temperature difference across the plastic. Next, the heat flux flowing into the quartz tube was calculated from the difference between the measured input power to the heater and the heat escaping from the sides of the plastic. 
The accuracy of the heat flux calculation was estimated to be approximately $\pm 1.7 \mathrm{~kW} / \mathrm{m}^{2}$. The estimated accuracy of the inner tube wall temperature $\left(T_{w i}\right)$ calculation was $\pm 0.2 \mathrm{~K}$. The $T_{w i}$ was extrapolated from the measured temperature of the outer brass strip, using the calculated heat flux and a radial conduction model.

The two-phase heat transfer coefficient $\left(\mathrm{h}_{2 \phi}\right)$ was calculated from:

$$
h_{2 \phi}=\frac{q^{\prime \prime}}{T_{w i}-T_{s}}
$$

where the saturation temperature $\left(T_{s}\right)$ was determined from the measured pressure to within $0.8 \mathrm{~K}$. The accuracy of the heat transfer coefficient measurement for most of the data was estimated to be $\pm 10 \%$ of the measured value.

The lubricant mass fraction (W) was calculated using a modification of the procedure given in ASHRAE Standard 41.1-84 (ASHRAE 1984). The lubricant mass fraction is the ratio of mass of the lubricant to the total mass of the lubricant and refrigerant in the mixture. The results of three 30-60 g samples were averaged. The refrigerant was evaporated from the lubricant by means of a 48 hour evacuation. The mass fraction measurement was estimated to be accurate to within 0.0005 in mass fraction. 


\section{VISUAL TECHNIQUE}

A high-speed $16 \mathrm{~mm}$ camera with a macro lens was used to film the boiling process simultaneously with the heat transfer measurements. All films were color and taken at approximately $6000 \mathrm{fps}$. The film speed was calculated with the aid of timing marks on the film to within $1.3 \%$ of the measured value. All flow qualities were near $1 \%$. The fluid temperature entering the quartz tube that was measured with a thermocouple always agreed within $\pm 1 \mathrm{~K}$ of the saturation temperature obtained from the corresponding measured pressure. The flow pattern from a typical test is presented in Fig. 3. The liquid entering the quartz tube was free of bubbles with the exception of the large plug of vapor that traveled along the top of the tube.

The film images were corrected for optical distortions induced by the curvature of the quartz tube. Both the angle of the major axis of the bubble with respect to the axis of the tube $(\theta)$ and its size were altered by the curvature of the tube, see Fig. 3. The aberrations could have been lessened by filling the cavity between the tube and the protective housing with a liquid having an index of refraction that closely matched that of the tube. Doing this would have compromised the heat transfer measurements since the amount of heat leaving the edges of the heater would have been increased by the presence of the liquid. Figure 4 shows the optical correction curves that were generated to correct the size of the bubbles after scaling the dimensions from the outer diameter of the tube. The ordinate is the ratio of the radial height of the image $\left(\mathrm{H}_{\mathrm{j}}\right)$ to that of the actual object $\left(\mathrm{H}_{\mathrm{o}}\right)$ within the 
tube. The abscissa is the radial distance from the center of the tube. The real image is magnified by a relatively constant value with the exception of a small region very close to the tube wall where it is reduced.

It was necessary to determine the actual orientation of the bubble to calculate the actual length of the major radius $\left(\mathrm{a}_{\mathrm{o}}\right)$ of the bubble. The following equation was developed (McClain, 1992) to find the true angle that the major axis of the bubble made with respect to the tube axis $\left(\theta_{0}\right)$ :

$$
\theta_{0}=\frac{1}{2} \operatorname{arccot} \frac{I_{a}-I_{c}}{I_{b}}
$$

where

$$
\begin{aligned}
& I_{a}=a_{i}{ }^{2} \sin ^{2} \theta_{i}+b_{i}{ }^{2} \cos ^{2} \theta_{i}, \\
& I_{b}=\frac{2 H_{i}\left(b_{i}{ }^{2}-a_{i}{ }^{2}\right) \sin \theta_{i} \cos \theta_{i}}{H_{0}}, \\
& I_{c}=\frac{{H_{i}}^{2}\left(a_{i}{ }^{2} \cos ^{2} \theta_{i}+b_{i}{ }^{2} \sin ^{2} \theta_{i}\right)}{H_{o}{ }^{2}}
\end{aligned}
$$

The $a_{i}$ and the $b_{i}$ are the minor and major radii of the distorted bubble. The $\theta_{0}$ and the $\theta_{\mathrm{i}}$ are the angles of the major axis with respect to the tube axis for the object and the image, respectively. The preceding bubble dimensions are illustrated in Fig. 3 where $\theta_{i}$ is negative since it is in the fourth quadrant. The bubble image is not rotated if $I_{b}=0$ since the bubble cross section is circular. 
The following equations relate the actual major and minor radii of the object $\left(a_{o}\right.$ and $\left.b_{0}\right)$ to the radii of the image and the actual bubble angle (McClain, 1992):

$$
\begin{aligned}
& a_{0}=\frac{a_{i} b_{i}}{\sqrt{I_{a} \cos ^{2} \theta_{0}+I_{b} \sin \theta_{0} \cos \theta_{0}+I_{c} \sin ^{2} \theta_{0}}} \\
& b_{0}=\frac{a_{i} b_{i}}{\sqrt{I_{a} \sin ^{2} \theta_{0}-I_{b} \sin \theta_{0} \cos \theta_{0}+I_{c} \cos ^{2} \theta_{0}}}
\end{aligned}
$$

One cautionary note: if the value obtained from eqn. 7 is larger than that obtained from eqn. 6 then eqn. 7 gives the value for the major radius and $\pi / 2$ should be subtracted from the object angle which was obtained from eqn. 2. Otherwise, no corrections are necessary to the above optical equations.

The volume and the minor radius of the bubble were calculated from its major radius and the cross-sectional area of the actual bubble $\left(A_{o}\right)$. The $A_{o}$ was obtained from the measured cross-sectional area of the bubble image $\left(A_{i}\right)$ as:

$$
A_{0}=A_{i}\left(\frac{H_{0}}{H_{i}}\right)^{2}
$$

The major diameter was obtained by longitudinally splitting the area of the bubble in half with a line in the general direction of the major axis and measuring the distance from the two points of the line that intersect the bubble edges. It was assumed that surface-tension and drag forces cause the bubble to be symmetric about its major axis. Accordingly, the 
bubble volume was obtained by revolving the bubble about its major axis. The ellipsoidal volume was calculated from:

$$
V_{0}=\frac{4 A_{0}^{2}}{3 \pi a_{0}}
$$

The accuracy of the volume calculation for two confidence intervals was estimated to be within $22 \%$ of the measured value.

A typical film-trace is depicted in Fig. 3. The film-traces were used to calculate several quantities including the amount of energy required to generate the bubbles $\left(q_{n}\right)$. Three different types of bubbles were defined to facilitate the calculation. The first set of bubbles, the zero-bubbles, are bubbles that are close to the heated surface under the zero time line. The time line is an arbitrarily chosen reference line below which all bubbles are analyzed. The time line moves such that the bubbles that were originally above the zero time remain above it and newly generated bubbles are below it. The second set of bubbles, the end-bubbles, are all of the bubbles which are under the time line after it has progressed from time-zero to some finite time interval $\Delta \mathrm{t}$. The difference between the 
volume of all of the end-bubbles and the volume of all of the zero-bubbles along with the time interval $\Delta t$ and the film speed are used to calculate the $q_{n}$ from:

$$
q_{n}=\frac{\left(V_{e}-V_{z}\right) f p s \rho_{v} h_{f g}}{N_{f}}
$$

The estimated accuracy of $\mathrm{q}_{\mathrm{n}}$, for a $68 \%$ confidence interval, varied from $10 \%$ to $80 \%$ of the measured value, and was typically within $25 \%$ of the measured value.

The third set of bubbles, the track-bubbles, are bubbles at discrete intervals of time along the time interval $\Delta \mathrm{t}$. The track-bubbles are used to determine the amount of heat the bubbles receive or release after they have departed from the wall. This heat is used to correct $\mathrm{q}_{\mathrm{n}}$ so that only the heat used to generate the bubbles $\left(\mathrm{q}_{\mathrm{g}}\right)$ is accounted for. The following equation was developed to approximate the corrected nucleative energy:

$$
q_{g}=q_{n}-\frac{1}{2} \frac{d q_{n}}{d N_{f}} \text { fps }\left(N_{\theta}-N_{z}\right)
$$

where $\mathrm{dq}_{\mathrm{n}} / \mathrm{dN}_{\mathrm{f}}$ is the average rate of change in the energy received by the bubbles with respect to the number of filming frames. The magnitude of $\mathrm{dq}_{\mathrm{n}} / \mathrm{dN}_{\mathrm{f}}$ is equal to the slope obtained from a linear regression of a plot of $\mathrm{q}_{\mathrm{n}}$ versus $\mathrm{N}_{\mathrm{f}}$. The correction was positive approximately as many times as it was negative. The magnitude of the correction was typically $10 \%$ of $\mathrm{q}_{\mathrm{n}}$. The sole purpose of the track-bubbles was to obtain this rate of energy exchange for use in eqn. 11 . 


\section{CALORIMETRIC RESULTS}

\section{Pure R11 and Pure 123}

The two-phase heat transfer coefficients of four different fluids were investigated: (1) R11, (2) R123, (3) R123 and 0.55\% alkylbenzene, and (4) R123 and 2\% alkylbenzene. A11 measurements were taken at the same reduced pressure $\left(\mathrm{P}_{\mathrm{r}}\right)$ of 0.03 and a flow quality of near $1 \%$. Heat transfer data were taken for Reynolds numbers varying from nearly 0.0 to 9500 at three different heat fluxes $\left(15,20\right.$, and $\left.30 \mathrm{~kW} / \mathrm{m}^{2}\right)$. Figures 5 through 7 are plots of the horizontal two-phase heat transfer coefficient versus the Reynolds number for the three different heat fluxes. Each figure includes the data of R123 so that a comparison between R123 and R123/1ubricant mixtures and R11 and its replacement refrigerant can be readily made.

Figure 5 compares the heat transfer coefficients of R11 to its nearly ozone-safe replacement R123. The heat transfer coefficient of $\mathrm{R} 123$ is larger than that of $\mathrm{R} 11$ for an equal heat flux and Reynolds number. At a zero Reynolds number condition, the heat transfer coefficient for $\mathrm{R} 123$ is $30 \%$ to $42 \%$ greater than that for $\mathrm{R} 11$. The heat transfer advantage of R123 steadily decreases with increasing Reynolds number. If data for R11 and R123 are extrapolated to Reynolds numbers greater than 10,000 , one would anticipate that the heat transfer coefficient for R11 would exceed that for R123. This is consistent 
with the measured data of Kedzierski and Didion (1991), who observed that the heat transfer coefficient for R11 in the nucleate flow boiling regime is indeed higher than that for R123 for Reynolds numbers of 18,000 and 24,000 .

Perhaps, the mechanism associated with the elevation of the heat transfer coefficient with respect to an increase in the Reynolds number for the nucleate flow boiling data presented here is similar to the mechanism which causes higher heat transfer coefficients for tubes in the upper rows of a smooth-tube flooded evaporator. Stephan and Mitrovic (1981) have found that the convective enhancement that is present for smooth tube bundles is not observed for bundles containing reentrant type tubes. Unlike boiling on an enhanced surface where the boiling is sheltered from convection and thus not dependent upon it, the nucleation on a smooth surface is exposed to the convection and influenced by it. Consequently, nucleate flow boiling within an enhanced tube would probably exhibit less of a Reynolds number dependence than that shown here.

The heat transfer coefficient increases nearly linearly with respect to Reynolds number for both fluids. The data for each heat flux for each fluid are nearly parallel to one another, indicating that the rate of increase in $h_{t p}$ with respect to $R e$ is independent of the incident heat flux. Also, notice that the Reynolds number has more of an effect on the heat transfer of R11 than it does on R123. For example, the two-phase heat transfer coefficient for R11 increases by an average of $37 \%$ for an increase in Re from 0 to 9500 . For the same increase in the Reynolds number, the R123 heat transfer increases by only $10 \%$. 
For both R11 and R123, the heat flux has a much greater effect on the heat transfer coefficient than the Reynolds number. For example, a $33 \%$ increase in the heat flux from 15 to $20 \mathrm{~kW} / \mathrm{m}^{2}$ corresponds to an average increase in the heat transfer coefficient of $22 \%$ for both R11 and R123. Likewise, a $50 \%$ increase in the heat flux from 20 to $30 \mathrm{~kW} / \mathrm{m}^{2}$ corresponds to an average increase in the heat transfer coefficient of $56 \%$ for $\mathrm{R} 11$ and $46 \%$ for R123. Clearly, this boiling phenomenon is heat flux driven, which is what one would expect given it is for a constant heat flux boundary condition.

\section{$\underline{\text { R123 and Alkylbenzene Mixture }}$}

It was assumed that the change in the boiling point of R123 due to the addition of the lubricant was negligible. This assumption is justified by two arguments. First, Stephan (1963) has reported that the boiling point of $\mathrm{R} 12$ increases by less than $0.3 \mathrm{~K}$ with an addition of $10 \%$ oil by weight. The lubricant mass fractions measured here are $2 \%$ and $0.5 \%$ which should cause a comparatively small change in the boiling point. Second, no change in the agreement between the measured saturation temperature and the saturation temperature obtained from the measured pressure was observed with the addition of alkylbenzene to the R123.

The properties of the refrigerant/lubricant mixture were evaluated at the saturation temperature of the pure refrigerant. The liquid density of the lubricant $\left(\rho_{\mathcal{L}}\right)$ and the kinematic viscosity of the lubricant $\left(\nu_{L}\right)$ were fitted to limited data (Chevron, 1992) as a 
function of temperature in kelvins. The liquid density of the lubricant in kilograms per cubic meters was fitted to the form:

$$
\rho_{L}=919.69+0.1994 T_{s}-0.001318 T_{s}^{2}
$$

The kinematic viscosity of the alkylbenzene lubricant in square meters per second was fitted to the form:

$$
v_{L}=5.6054 \times 10^{-11} \exp \frac{4308.70}{T_{s}}
$$

The following ideal mixing rule was used to approximate the dynamic viscosity of the refrigerant/lubricant mixture:

$$
\mu_{m}=\exp \left\{W \ln \mu_{L}+(1-W) \ln \mu_{I}\right\}
$$

The surface-tension between the liquid lubricant and air/lubricant vapor $\left(\sigma_{\mathrm{lv}}\right)$ was calculated from the rise height in a $1.2 \mathrm{~mm}$ bore capillary tube. The surface-tension was found to be approximately $0.026 \mathrm{~N} / \mathrm{m}$ at $296.4 \mathrm{~K}$. The surface-tension of R123 was obtained from Chae et al. (1990). The surface-tension of R11 was obtained from the International Institute of Refrigeration (1982).

Figure 6 compares the measured two-phase heat transfer coefficient of pure R123 to a mixture of R123 and 0.55 weight percent of alkylbenzene. The heat transfer coefficient 
is plotted versus the liquid Reynolds number. Two aspects of the comparative heat transfer are evident from the figure. First, the addition of $0.5 \%$ alkylbenzene to pure R123 enhances the heat transfer for all heat transfer conditions. Overall, the heat transfer coefficient of the R123/0.5\% mixture, averaged for all Reynolds numbers and heat fluxes, is $16 \%$ greater than the overall averaged heat transfer coefficient for pure R123. Second, the addition of the lubricant to R123 has caused the heat transfer to be more responsive to an increase in the Reynolds number. For example, the heat transfer coefficient for the R123/0.5\% alkylbenzene mixture increases roughly by $44 \%$ and $11 \%$ for an increase in the Reynolds number from zero to 9,500 for the two lower heat flux conditions and the highest heat flux condition, respectively. As a result, the enhancement of the R123/0.5\% alkylbenzene mixture heat transfer relative to that of pure R123 increases with Reynolds number.

Figure 7 compares the measured two-phase heat transfer coefficient of pure R123 to a mixture of R123/2.\% weight percent of alkylbenzene. The heat transfer coefficient of the R123/2\% alkylbenzene mixture can be examined in terms of: (1) its relative magnitude compared to the pure component, and (2) the influence of the Reynolds number upon it. Examination of the first point above reveals that the heat transfer coefficient of the R123/2\% alkylbenzene mixture, averaged over all heat transfer conditions, is $11 \%$ greater than that for pure R123. This is approximately two-thirds of the enhancement associated with the $0.5 \%$ mass fraction fluid. A study of the second point above indicates that the rate of increase for the $\mathrm{R} 123 / 2 \%$ alkylbenzene mixture is greater than that for pure $\mathrm{R} 123$ 
and it is a also a function of the heat flux. For example, an increase in the Reynolds number from zero to 9,500 causes a $75 \%, 26 \%$ and a $23 \%$ increase in the heat transfer coefficient for the $15 \mathrm{~kW} / \mathrm{m}^{2}, 20 \mathrm{~kW} / \mathrm{m}^{2}$, and $30 \mathrm{~kW} / \mathrm{m}^{2}$ heat flux conditions, respectively. Averaged over all heat transfer conditions, the percent increase in the heat transfer coefficient with respect to increased Reynolds number for the $2 \%$ mass fraction mixture is more than twice as large as it is for the $0.5 \%$ mixture.

Perhaps the increase in the rate of increase in the heat transfer coefficient with respect to the Reynolds number is related to the increase in the liquid thermal conductivity and the liquid Prandtl number. The thermal conductivity of the $2 \%$ alkylbenzene mixture is $0.2 \%$ greater than that of the pure fluid. The Prandtl number of the $2 \%$ mixture is $12 \%$ greater than that of the pure fluid.

\section{Correlation of Heat Transfer Coefficient}

It is difficult to find a heat transfer correlation that applies strictly to horizontal nucleate flow boiling. One candidate correlation form might be a superposition model. Historically, these correlations are generated from a statistical fit of many flow boiling data sources from many different metal tubes. Typically, the effect of surface roughness is not included in the correlation of a superposition model. Yet, as Corty and Foust (1955) have shown, pool boiling strongly depends upon the surface finish. Therefore, rather than comparing the present data with a superposition model for flow boiling, the 
present data for a zero Reynolds number are compared to three different pool boiling correlations which account for surface roughness effects.

Agreement between the measured heat transfer coefficients and two of the correlations was not acceptable. On average, the heat transfer coefficient for R11 obtained from Cooper's equation (1984) was overpredicted by approximately 300\%. Likewise, his equation overpredicted the heat transfer coefficient for R123 by approximately $200 \%$. Similarly, poor agreement was achieved with Stephan's and Abdelsalam's (1980) pool boiling equation for refrigerants with the correction for surface roughness.

Good agreement was achieved between the measured heat transfer coefficient at $\operatorname{Re}=0$ and the correlation with the Borishanskii-Minchenko equation (Borishanskii et al., 1969):

$$
h_{2 \phi}=\frac{E K_{p}^{0.7 P e^{0.7} k_{1}}}{\sqrt{\frac{\sigma}{g\left(\rho_{1}-\rho_{V}\right)}}}
$$

where $K_{p}$ is the dimensionless pressure:

$$
K_{p}=\frac{P_{s}}{\sqrt{g \sigma\left(\rho_{1}-\rho_{v}\right)}}
$$


and the Peclet number $(\mathrm{Pe})$ is:

$$
P e=\frac{q^{\prime \prime} \rho_{1} c_{p_{1}}}{h_{f g} \rho_{v} k_{1}} \sqrt{\frac{\sigma}{g\left(\rho_{1}-\rho_{v}\right)}}
$$

Equation 15 and the measured heat transfer coefficients for $\mathrm{R} 11$ and $\mathrm{R} 123$ at $\mathrm{Re}=0$ agreed to within $\pm 12 \%$ when the dimensionless boiling constant $E$ was set equal to 2.5 $\times 10^{-4}$. Rice and Calus (1972) correlated the pool boiling data from an electroplated chromium surface of Cichelli and Bonilla (1945) to the Borishanskii-Minchenko equation

with the constant $E=3.92 \times 10^{-4}$. Although roughness values for this surface were not given, a typical $R_{a}$ roughness for an electroplated surface is approximately $0.8 \mu \mathrm{m}$ (Baumeister, 1978). If the constant for Cichelli's and Bonilla's data were to be used to predict the present R11 and R123 data, the data would be overpredicted by an average of $60 \%$. However, this value of $\mathrm{E}$ may be inappropriate for the quartz tube since the roughness of the chromium surface is greater than that of the quartz tube. Consequently, the value of $E=2.5 \times 10^{-4}$ for the quartz tube seems to be consistent with Cichelli's and Bonilla's data since one would expect that the value of E for the quartz tube would be smaller than that for the chromium surface.

\section{VISUAL RESULTS}

Visual data with an acceptable statistical certainty is difficult to obtain for two reasons: (1) the cost of frequent repetition of visual measurements is prohibitive, and (2) the time for 
which data is taken is of the order of milliseconds. If the boiling process is cyclic, the problem of a limited data sample is worsened.

Vapor production during nucleate flow boiling can vary with respect to time for what is viewed calorimetrically as steady state heat transfer. Strenge et al. (1961) and Schultz and Cole (1978) have noted the fluctuating behavior of nucleate boiling. Mesler and Banchero (1958) noticed that during the boiling of organic liquids, the surface temperature fluctuations decreased for higher pressures and higher heat fluxes. The temperature fluctuations were not noticeable for pressures above atmospheric pressure.

All of the data presented here are for pressures slightly above atmospheric. The hope is that the amplitude of the fluctuations is small since the data are taken for a small time interval ( 0.025 seconds). However, the amplitude of the fluctuation can be measured only with repeated measurements. If the amplitude of the fluctuation is small, then averaging a large amount of data is not as important. It is likely that an adequate average for the bubble diameter and the contact angle can be obtained since these have sufficient numbers for averaging. However, the site density and the bubble frequency are more strongly dependent upon the variations of the ebullition cycle. Consequently, as Kedzierski and Didion (1990) have found, the fluctuations of the bubble frequency and the site density are greater than those of the bubble diameter and contact angle. Therefore, a cautious view should be taken toward the bubble frequency and the site density data for a particular heat flux and Reynolds number. For most cases, the data have been gathered from one film 
with a duration of approximately one second. In other words, the frequency and site density data for a particular heat transfer condition represent an event which may not necessarily be the most probable event, i.e., the average event.

Foaming occurred for the zero Reynolds number condition for all of the refrigerant/lubricant mixtures. Foaming caused nearly a $50 \%$ increase in the bubble diameter and approximately a 50\% reduction in the bubble flux. Consequently, only the non-zero Reynolds number data for the bubble flux or the bubble diameter were included in the calculation of the overall averages so that a fair comparison between each fluid could be made.

\section{Contact Angle}

The dynamic and the static contact angles of all of the fluids were measured. All test fluids fully wetted a clean glass surface when placed on the surface as liquid droplets. Wetting implies that the static contact angle is zero. The dynamic contact angles were obtained from the film-traces. Figure 3 defines the contact angle $(\beta)$ as it was measured here.

Figure 8 shows the measured contact angle for the four fluids versus Reynolds number. Approximately ten contact angles were average from each film-trace. A linear line fitted through the data would indicate that the contact angle increases slightly with respect to the 
Reynolds number. This makes intuitive sense since if a bubble is not abruptly stripped from the wall by drag forces it will grow more slowly and tend to flatten out resulting in a smaller contact angle. However, an average value for the contact angle may prove more convenient since the influence of the Reynolds number on the contact angle is relatively small.

The present measured average contact angles confirm the approximate contact angle for refrigerants of $35^{\circ}$ cited by Stephan and Abdelsalam (1980). Row 1 of table 1 presents the contact angles for each fluid averaged over all heat transfer and flow conditions. For example, the average measured contact angle for pure $\mathrm{R} 11$ was $31^{\circ}$ which is only $12 \%$ greater than the that given by Stephan and Abdelsalam (1980). The average measured contact angle for pure $\mathrm{R} 123,36^{\circ}$, agrees closely with $35^{\circ}$. The addition of alkylbenzene to R123 resulted in a larger contact angle. Specifically, the average contact angle for R123 and $0.55 \%$ and $2 \%$ alkylbenzene were $40^{\circ}$ and $41^{\circ}$, respectively.

Row 2 of table 1 presents the estimated standard deviation of the contact angle measurement $\left(s_{\beta}\right)$. A portion of the deviation of the measurement may be due to the variation of the contact angle while the bubble grows. 


\section{Bubble Diameter}

The bubble diameter appeared to be independent of the Reynolds number and the heat flux. The cyclic characteristics of boiling should not have a significant effect on the size of the bubble. Surface-tension and the contact angle should be the primary factors in determining the bubble diameter. Therefore, given the above two conditions, an average of all the bubbles for a particular fluid should result in a fair representation of the average bubble diameter for that fluid at a given thermodynamic state.

An equivalent spherical bubble diameter $\left(D_{s}\right)$ was calculated from the average volume of the zero-bubbles. The average diameter of the zero-bubbles should closely represent the departure diameter. The accuracy of the bubble diameter measurement for two confidence intervals was estimated to be within $7 \%$ of the calculated value. Row 3 of table 1 presents the average equivalent spherical diameters for the four fluids for non-zero Reynolds numbers. Row 4 of table 1 shows the standard deviation from the average bubble diameter for each fluid.

Fritz (1935) utilized the work of Bashforth and Adams (1883) to calculate the maximum volume of a spherical vapor bubble as a function of Laplace's constant and the contact angle $\beta$ (in degrees) with respect to the solid surface. Fritz's solution is presented in 
graphical and tabular form. The tabulated solution can be fitted to the following familiar equation for the departure diameter attributed to Fritz:

$$
D_{d}=0.0204 \beta \sqrt{\frac{\sigma}{g\left(\rho_{1}-\rho_{v}\right)}}
$$

The Fritz equation does a remarkable job of predicting the data for such a simple equation. When the measured contact angle and the fluid properties are substituted into eqn. 18, the agreement between the equation and the measured bubble diameter for $\mathrm{R} 123$ is within $1 \%$. Equation 18 underpredicts the bubble diameter for R11 by approximately $16 \%$. However, the Fritz equation does not predict the effect of the addition of lubricant to the refrigerant. Nevertheless, it predicts the measured bubble diameter for the R123/0.55\% alkylbenzene and the R123/2\% alkylbenzene mixtures within $14 \%$ and $35 \%$, respectively.

\section{$\underline{\text { Site Density }}$}

The determination of the site density was subjective. It was difficult to determine exactly how many sites were active since some sites were very close to each other. A best guess was made concerning the average number of locations from which bubbles originated. The surface area was calculated from the product of the measured width of the heater and the scaled length of the analyzed region obtained from the film-trace. 
Figure 9 shows the heat flux dependency on the nucleation site density for all four fluids. The symbols represent the measured data. The solid lines are best fit regressions of the data to the form:

$$
q^{\prime \prime}=C_{n} n^{B}+D_{n}
$$

where the constant $D_{n}$ was set to zero for all of the fluids with the exception of the R123/2\% alkylbenzene mixture. A linear fit was best for this data. The B exponents for the other R123 fluids were also close to 1 , namely, 0.91 for R123 and 1.24 for R123 and $0.5 \%$ alkylbenzene. The exponent for the site density for the R11 was 0.46 which was smaller than that for the R123 fluids. The values for B are summarized in row 5 of table 1.

The B exponent for the fluids tested here does not vary significantly from that reported in the literature. Hsu and Graham (1976) remark that, although the constant $\mathrm{C}_{\mathrm{n}}$ varies greatly depending upon the fluid and the surface, the exponent has a relatively small range of variance between about 0.3 and 0.8 . Kirby and Westwater (1965) have measured an exponent for the nucleation site density on a glass surface and found it to be approximately equal to 0.73 .

The addition of a small amount of alkylbenzene $(0.5 \%)$ to $\mathrm{R} 123$ increases the number of active nucleation sites by approximately 5 sites $/ \mathrm{cm}^{2}$. Further increase in the amount of alkylbenzene to the $\mathrm{R} 123$ reduces the number of active sites to approximately the value for 
that of R11. For the same heat flux, R11 has approximately 10 less active sites $/ \mathrm{cm}^{2}$ than those of R123. The sixth row of table 1 summarizes the site density measurements.

\section{Bubble Flux}

The bubble frequency flux $f^{\prime \prime}$ is the total number of bubbles emitted from a surface per unit area per unit time. The bubble frequency flux was calculated as:

$$
f^{\prime \prime}=\frac{q_{g}}{A \rho_{V} h_{f g} \bar{V}_{z}}
$$

The accuracy of the bubble flux calculation was estimated to be approximately $33 \%$ for two confidence intervals.

It appears that the bubble flux is approximately the same for all fluids. Row 7 of table 1 gives the bubble frequency flux averaged over all non-zero Reynolds number heat transfer conditions for each of the fluids. The estimated standard deviation of the bubble flux measurement $\left(\mathrm{s}_{\mathrm{f}}\right)$, given in row 8 , is nearly greater than the measurement. Therefore, the bubble fluxes for each fluid cannot be given a strict relative ranking. The bubble flux is enhanced for small lubricant mass fractions $(0.5 \%)$ with caveat that the standard deviation of this measurement is large. 
The average bubble frequency for a single bubble is obtained by multiplying the frequency flux by the site density. Rows 9 and 10 of table 1 gives the measured frequency and the estimated standard deviation of the measurement, respectively. Based on the work of Jakob (1949), Zuber (1959) developed an equation for the frequency of a single bubble:

$$
f=\frac{0.59}{D_{d}} \sqrt[4]{\frac{\sigma g\left(\rho_{1}-\rho_{v}\right)}{\rho_{1}^{2}}}
$$

Predicted values of $f$ from eqn. 21 lie within the fluctuations of the measured $f$. The equation underpredicts the measured average bubble frequency $\overline{(f)}$ by approximately $100 \%$ for all of the test fluids. For example, eqn. 21 predicts the bubble frequency to be 74 bub/s for R11; the measured value averaged for all conditions is $178 \mathrm{bub} / \mathrm{s}$. The standard deviation of the individual measurements from this mean value is approximately $182 \mathrm{bub} / \mathrm{s}$. Similar results were obtained for the other fluids which are presented in row 9 and 10 of table 1.

\section{MECHANISTIC INTERPRETATION OF $\mathrm{h}_{2 \phi}$}

The visual data were taken with a view to gaining some physical understanding of the calorimetric data. The model of Mikic and Rohsenow (1969) can be used as a tool for making the physical connection between the visual and the calorimetric data. Their model of the nucleate heat flux $\left(\mathrm{q}_{\mathrm{n}}{ }_{\mathrm{n}}\right)$ is: 


$$
q_{n}^{\prime \prime}=2 \sqrt{k_{1} \rho_{1} C_{p_{1}} \pi} \sqrt{f} D_{d}^{2} n \Delta T_{s}
$$

This model is based on the assumption that the latent heat is not important in determining the heat transfer due to nucleation. Instead, the governing mechanism is the transport of the superheated liquid layer from the wall by the motion of the bubble. Consequently, eqn. 22 is based on a transient conduction analysis on an unit area which is twice the bubble diameter. Lorenz et al. (1974) have validated this model for water and methanol pool boiling.

The heat transfer coefficient obtained from equation 22 consists of the multiplication of a fluid property part $\left(2\left\{\mathrm{k}_{\mathrm{l}} \rho_{1} \mathrm{c}_{\mathrm{pl}} \pi\right\}^{0.5}\right)$ and a bubble mechanism part $\left(\mathrm{f}^{1 / 2} \mathrm{D}_{\mathrm{b}}{ }^{2} \mathrm{n}\right)$. The second to the last row in table 1 shows that the fluid property terms for all of the fluids are within $1 \%$ of each other. Accordingly, the model suggests that the observed differences in the heat transfer coefficients for each fluid cannot be attributed to the differences in fluid transport properties. Consequently, the differences in the heat transfer coefficients from fluid to fluid must be due to differences in the bubble parameters.

The last row of table 1 gives the magnitude of the bubble mechanism term calculated using the average values for $f, D_{d}$ and $n$ which are given in table 1 . Comparison of the relative magnitudes of the bubble mechanism term for each fluid shows that this term is larger for the $\mathrm{R} 123 / 0.5 \%$ alkylbenzene mixture primarily due to the larger number of active nucleation sites associated with that fluid. The bubble diameter and the bubble frequency have not changed much with the addition of a small amount of lubricant. Consequently, 
part of the reason that the $\mathrm{R} 123 / 0.5 \%$ alkylbenzene heat transfer is greater than that of pure R123 is that the addition of lubricant has caused more sites to become active in generating bubbles. On the other hand, further increase in the lubricant mass fraction has decreased the bubble size and the site density which has contributed to a reduction in the heat transfer as compared to the $0.5 \%$ lubricant mass fraction. Likewise, the lower heat transfer coefficient of pure $\mathrm{R} 11$ as compared to that of pure $\mathrm{R} 123$ is primarily due to a lower number of active sites.

\section{CONCLUSIONS}

Bubble formation during horizontal flow boiling of R11, R123 and a R123/alkylbenzene mixture was investigated both visually and calorimetrically. The two-phase heat transfer coefficient of four different fluids were investigated: (1) R11, (2) R123, (3) R123 and $0.55 \%$ alkylbenzene, and (4) R123 and 2\% alkylbenzene. Good agreement was achieved between the measured heat transfer coefficients for R11 and R123 and the BorishanskiiMinchenko equation.

The relative magnitudes of the nucleate flow boiling heat transfer coefficient were compared to that of R123. For Reynolds numbers below 9,500, the heat transfer coefficient of R123 was on average $22 \%$ greater than that of R11 for equal heat flux and Reynolds number. The addition of alkylbenzene to pure R123 enhances the heat transfer relative to that of pure $\mathrm{R} 123$ for all heat transfer conditions. 
For both R11 and R123, an increase in either the heat flux or the Reynolds number increases the heat transfer coefficient. The heat flux has a much larger effect on the heat transfer coefficient than the Reynolds number. An increase in the heat flux caused nearly an equal percentage increase in the heat transfer coefficient. The two-phase heat transfer coefficient for R11 increases significantly more than that of R123 for an increase in Reynolds number. The addition of lubricant to the R123 caused the heat transfer to be more sensitive to an increase in the Reynolds number.

The average measured contact angle for pure R123 agrees closely with that reported in the literature: $35^{\circ}$ as compared to $36^{\circ}$. The addition of alkylbenzene to $\mathrm{R} 123$ resulted in a larger contact angle. Namely, the average contact angle for R123 and $0.55 \%$ and $2 \%$ alkylbenzene was $40^{\circ}$ and $41^{\circ}$, respectively.

Given the simplicity of the Fritz equation (eqn. 18), it does a remarkable job of predicting the measured bubble diameters: within $1 \%$ and $16 \%$ of the measured values for the pure R123 and R11, respectively. The addition of alkylbenzene caused a reduction in the average size of the bubble, which is not predicted by the Fritz equation. Even so, it predicts the measured bubble diameter for the R123/0.55\% alkylbenzene and the R123/2\% alkylbenzene mixtures within $14 \%$ and $35 \%$, respectively.

The addition of a small amount $(0.5 \%)$ of alkylbenzene to R123 increases the number of active nucleation sites by approximately 5 sites $/ \mathrm{cm}^{2}$. Further increase in the amount of 
alkylbenzene to the $\mathrm{R} 123$ reduces the number of active sites to approximately the value for that of R11. For the same heat flux, R11 has approximately 10 less active sites $/ \mathrm{cm}^{2}$ than that of R123.

Zuber's equation (eqn. 21 ) predicts the measured average bubble frequency $(\bar{f})$ to within the measurement uncertainty for all of the test fluids. The total flux of bubbles from the surface is approximately the same for all of the fluids.

Part of the reason that the $\mathrm{R} 123 / 0.5 \%$ alkylbenzene heat transfer is greater than that of pure R123 is that the addition of lubricant has caused more sites to become active in generating bubbles. The bubble diameter and the bubble frequency has not changed much with the addition of a small amount of lubricant. On the other hand, further increase in the lubricant mass fraction has decreased the bubble size and the site density which has contributed to a reduction in the heat transfer. Primarily a lower number of active sites has caused the pure R11 heat transfer to be lower than that of the pure R123. 


\section{REFERENCES}

ASHRAE, 1984, ASHRAE Handbook-1984 Systems, Atlanta: American Society of Heating, Refrigeration and Air-Conditioning, Inc., p. 29.14.

Bashforth, F., and Adams, J., 1883, Capillary Action, Cambridge, England.

Baumeister, T., Avallone, E. A., and Baumeister III, T., 1978, Marks' Standard Handbook for Mechanical Engineers, 8th ed., McGraw-Hill, New York.

Borishanskii, V. M., Bobrovich, G. I., and Minchenko, F. P., 1969, "Heat Transfer from a Tube to Water and to Enthanol in Nucleate Pool Boiling," Symposium on Problems of Heat Transfer and Hydraulics of Two-Phase Media, Ed. S. S. Kutateladze, Pergamon Press, London, pp. 85-106.

Chevron Chemical Company, 1992, Technical Data Sheet on Zerol Refrigeration Fluid 300.

Chae, H., B., Schmidt, J. W., and Moldover, M. R., 1990, "Surface Tension of Refrigerants R123 and R134a," J. of Chem. \& Eng. Data, Vol. 35, No. 1, pp. 6-8.

Cichelli, M. T., and Bonilla, C. F., 1945, Trans. AIChE, Vol. 41, pp. 755-787. 
Cooper, M. G., 1984, "Saturation Nucleate Pool Boiling-A Simple Correlation," Proc. 1st U.K. National Conf. on Heat Transfer, Vol. 2, pp. 785-793.

Corty, C., and Foust, A. S., 1955, "Surface Variables in Nucleate Boiling," Chem. Eng. Prog. Symp., Vol. 51, No. 16, pp. 1-12.

Fritz, W., 1935, "Berechnung des Maximalvolumens von Dampfblasen," Physik. Zeitschr., Vol 36, pp. 379-384.

Hsu, Y., and Graham, R. W., 1976, Transport Processes in Boiling and Two-Phase Systems, Including Near-Critical Fluids, Washington: Hemisphere.

International Institute of Refrigeration, 1982, Thermodynamic and Physical Properties of R11, Paris.

Jakob, M. 1949, Heat Transfer, Vol. 1, Wiley, New York.

Kedzierski, M. A., and Didion, D. A., 1990, "Visualization of Nucleate Flow Boiling for an R22/R114 Mixture and its Components," Experimental Heat Transfer, Vol. 3, pp. 447463. 
Kedzierski, M. A., and Didion, D. A., 1991, "A Comparison of Experimental Measurements of Local Flow Boiling Heat Transfer Coefficients for R11 and R123," ASME/JSME Thermal Engineering Proc., ASME, New York, Vol. 3, pp. 243-250.

Kirby, D. B., and Westwater, J. W., 1965, "Bubble and Vapor Behavior on a Heated Horizontal Plate during Pool Boiling Near Burnout," Chem. Eng. Prog. Symp. Ser., Vol. 61, No. 57, pp. 238-248.

Lorenz, J. J., Mikic, B. B., and Rohsenow, W. M., 1974, "Effects of Surface Conditions on Boiling Characteristics," Paper B2.1,4:35, 5th Int. Heat Trans. Conf., Tokyo

McClain, M., 1992, Personal communication, National Institute of Standards and Technology.

Mesler, R. B., and Banchero, J. T., 1958, "Effect of Superatmospheric Pressures on Nucleate Boiling of Organic Liquids," A.I.Ch.E. J., Vol. 4, No. 1, pp. 102-113.

Mikic, B. B., and Rohsenow, W. M., 1969, "New Correlations of Pool Boiling Data Including the Effect of Heating Surface Characteristics," J. Heat Trans., Vol. 91, pp.245250. 
Rice, P. and Calus, W. F., 1972, "Pool Boiling-Single Component Liquids," Chemical Engineering Science, Vol. 27, No. 9, pp. 1677-1687.

Rohsenow, W. M., 1988, "What We Don't Know and Do Know About Nucleate Pool Boiling Heat Transfer," ASME, HTD-Vol. 104, Collected Papers in Heat Transfer 1988 Vol. II, pp. 169-172.

Schultz, R. R., and Cole, R., 1978, "Bubble Nucleation and Growth Instabilities in Transient Boiling," Proc. 6th Int. Heat Trans. Conf., Toronto, Vol. 1, pp. 133-138.

Stephan, K., 1963, "Influence of Oil on Heat Transfer of Boiling Refrigerant 12 and Refrigerant 22," XI International Congress of Refrigeration.

Stephan, K., and Abdelsalam, M., 1980, "Heat Transfer Correlations for Natural Convection Boiling," Int. J. Heat Mass Transfer, Vol. 23, pp. 73-87.

Stephan, K., and Mitrovic, J., 1981, "Heat Transfer in Natural Convective Boiling of Refrigerants and Refrigerant-Oil Mixtures in Bundles of T-Shaped Finned Tubes," Advances in Enhanced Heat Transfer - 1981, Eds. R.L. Webb et al., ASME, New York, HTD-Vol. 18, pp. 131-146. 
Strenge, P. H., Orell, A., Westwater, J. W., 1961, "Microscopic Study of Bubble Growth During Nucleate Boiling," A.I.Ch.E Journal, Vol. 7, No. 4, pp. 578-583.

Zuber, N., 1959, "Hydrodynamic Aspects of Boiling Heat Transfer," Ph.D. thesis, University of California, Los Angeles. 
Table 1 - Visual Data Summary

\begin{tabular}{|c|c|c|c|c|}
\hline $\begin{array}{l}\text { Measured } \\
\text { Data }\end{array}$ & R11 & R123 & $\begin{array}{l}\text { R123/0.5\% } \\
\text { alkylbenzene }\end{array}$ & $\begin{array}{l}\mathrm{R} 123 / 2 \% \\
\text { alkylbenzene }\end{array}$ \\
\hline$\beta$ (deg.) & 31 & 30 & 40 & 41 \\
\hline$s_{\beta}$ (deg.) & 6 & 5 & 6 & 9 \\
\hline $\mathrm{D}_{\mathrm{s}}(\mathrm{mm})$ & 0.83 & 0.76 & 0.74 & 0.65 \\
\hline $\mathrm{s}_{\mathrm{Ds}}(\mathrm{mm})$ & 0.31 & 0.28 & 0.28 & 0.19 \\
\hline B & 0.46 & 0.91 & 1.24 & 1 \\
\hline $\mathrm{n} / 21.7 \mathrm{~kW} / \mathrm{m} 2\left(\mathrm{~cm}^{-2}\right)$ & 20 & 30 & 40 & 20 \\
\hline$f^{\prime \prime}\left(s^{-1} m^{-2}\right)$ & $380 \times 10^{5}$ & $390 \times 10^{5}$ & $490 \times 10^{5}$ & $370 \times 10^{5}$ \\
\hline$\sigma_{\mathrm{f}^{\mathrm{m}}}\left(\mathrm{s}^{-1} \mathrm{~m}^{-2}\right)$ & $290 \times 10^{5}$ & $190 \times 10^{5}$ & $250 \times 10^{5}$ & $270 \times 10^{5}$ \\
\hline$f\left(s^{-1}\right)$ & 178 & 144 & 146 & 251 \\
\hline$s_{f}\left(s^{-1}\right)$ & 182 & 54 & 75 & 164 \\
\hline $\begin{array}{r}2\left\{\mathrm{k}_{\mathrm{i}} \rho_{1} \mathrm{c}_{\mathrm{p}} \pi\right\}^{0.5} \\
\left(\mathrm{~J} \mathrm{~K}^{-1} \mathrm{~m}^{-2} \mathrm{~s}^{-0.5}\right)\end{array}$ & 1185 & 1172 & 1174 & 1179 \\
\hline $\mathrm{f}^{1 / 2} \mathrm{D}_{\mathrm{b}}^{2} \mathrm{n}\left(\mathrm{s}^{-.5}\right)$ & 1.84 & 2.08 & 2.65 & 1.34 \\
\hline
\end{tabular}




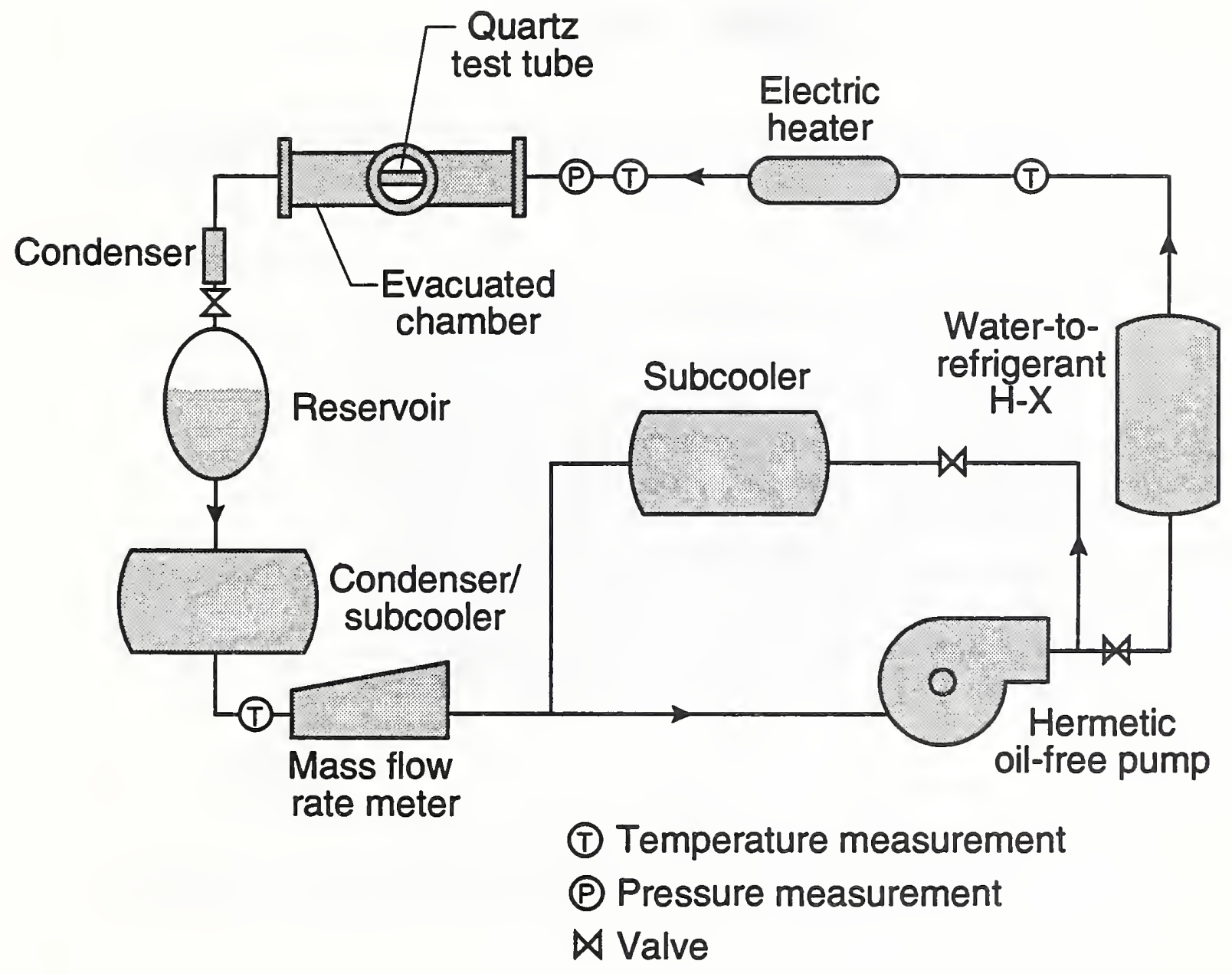

Fig. 1 Schematic of test apparatus 


\section{Fluid, $T_{s}$}

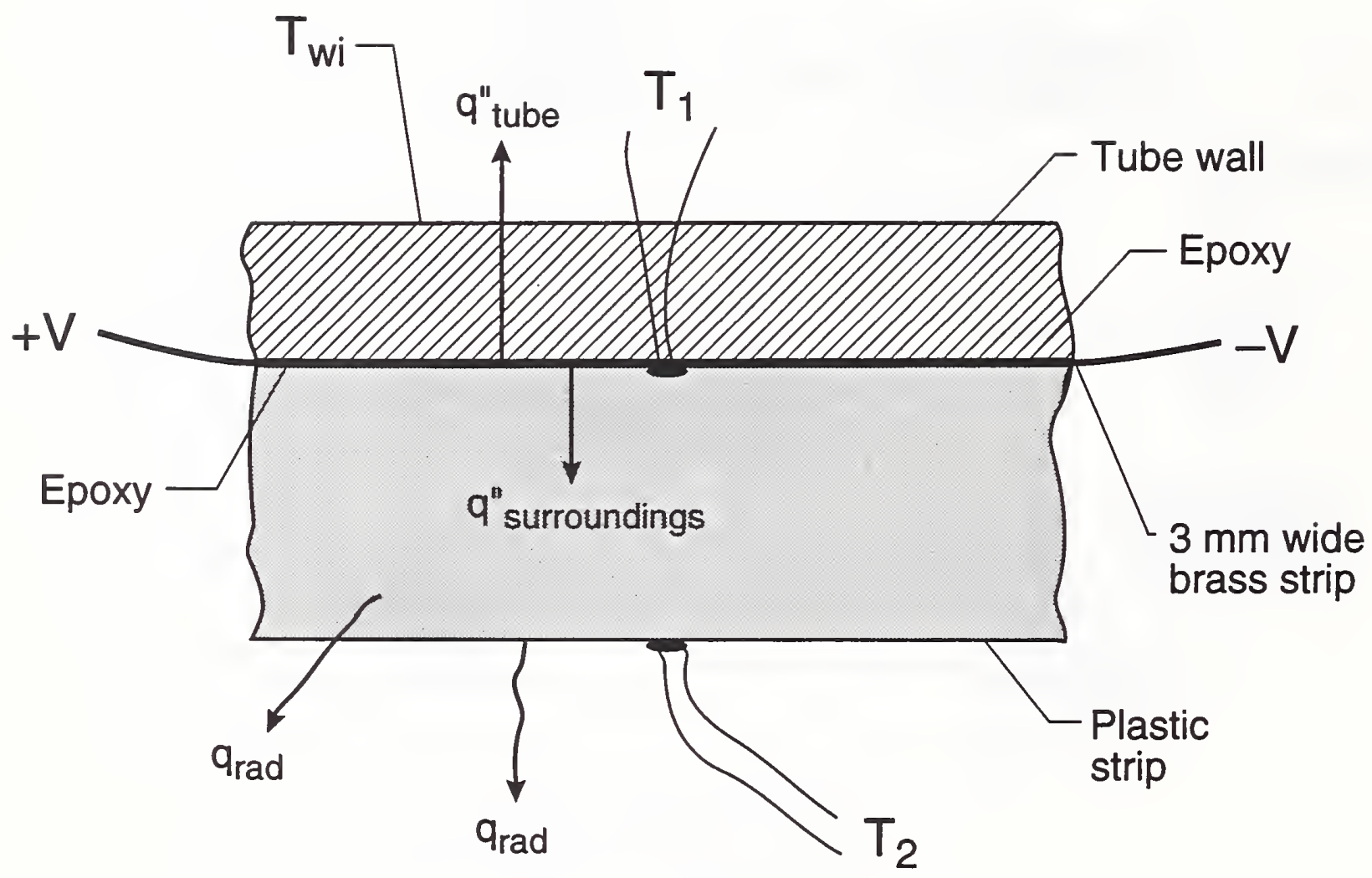

Fig. 2 Schematic of heater composite 

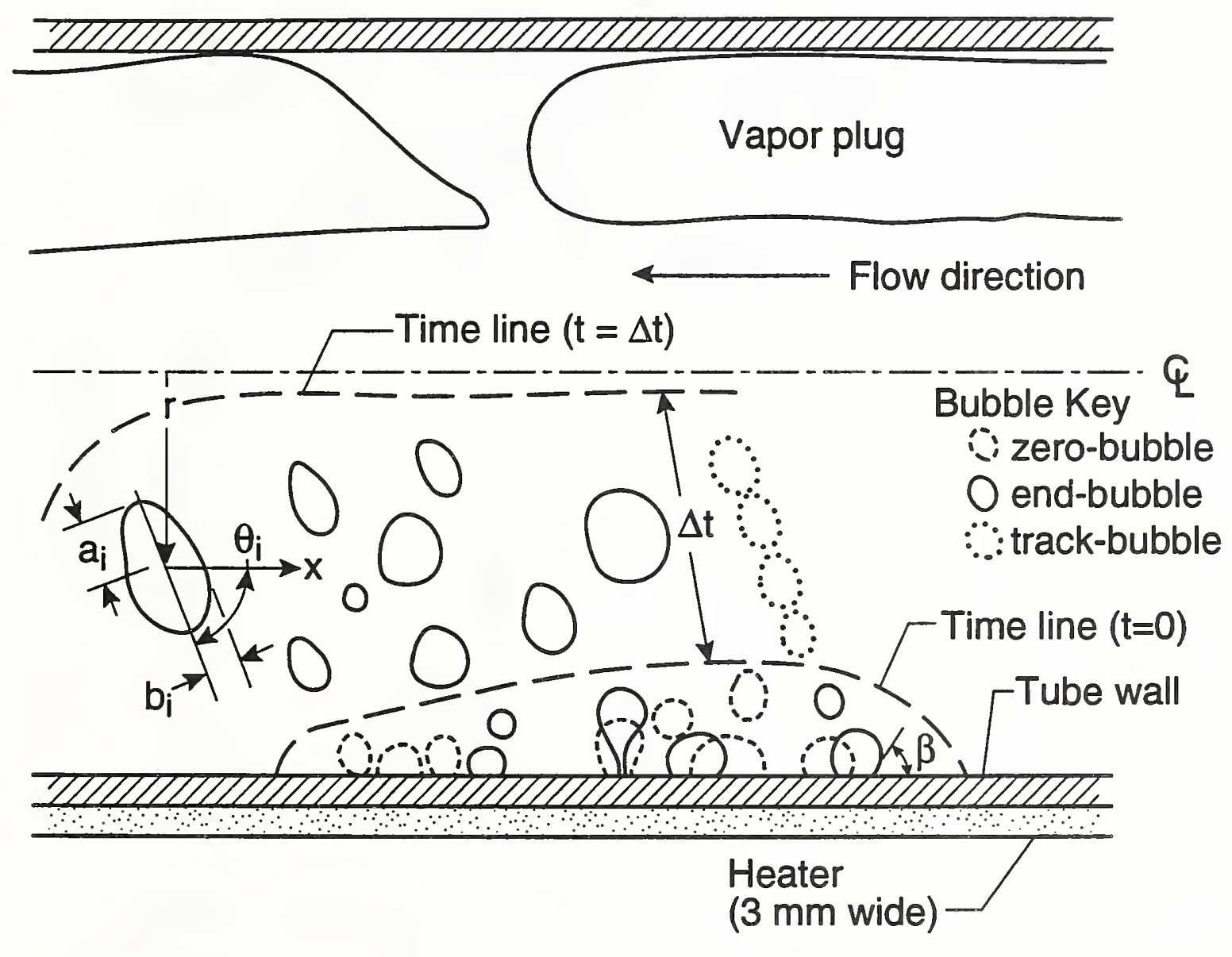

Fig. 3 Trace method and flow pattern 


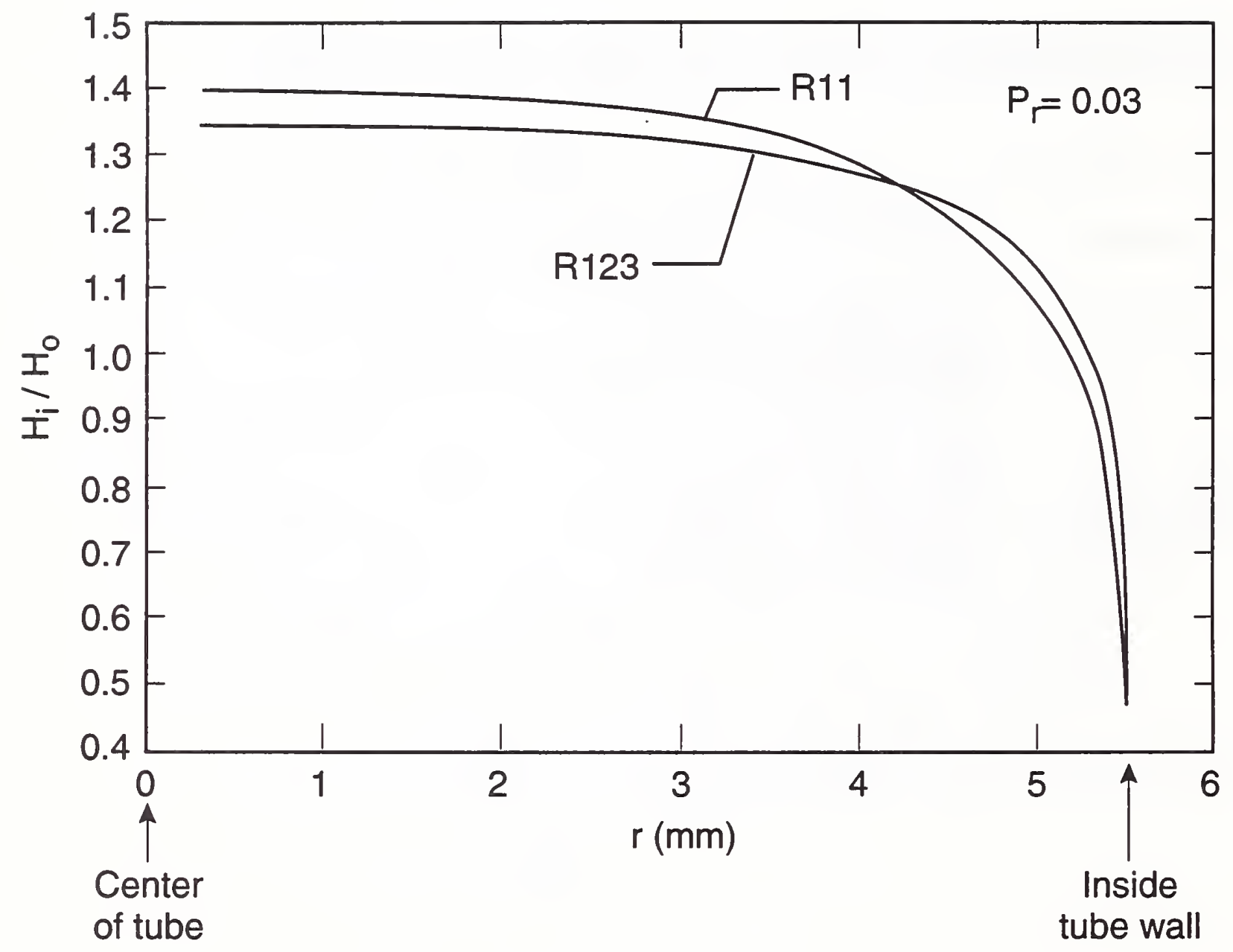

Fig. 4 Optical correction ratio for radial height 


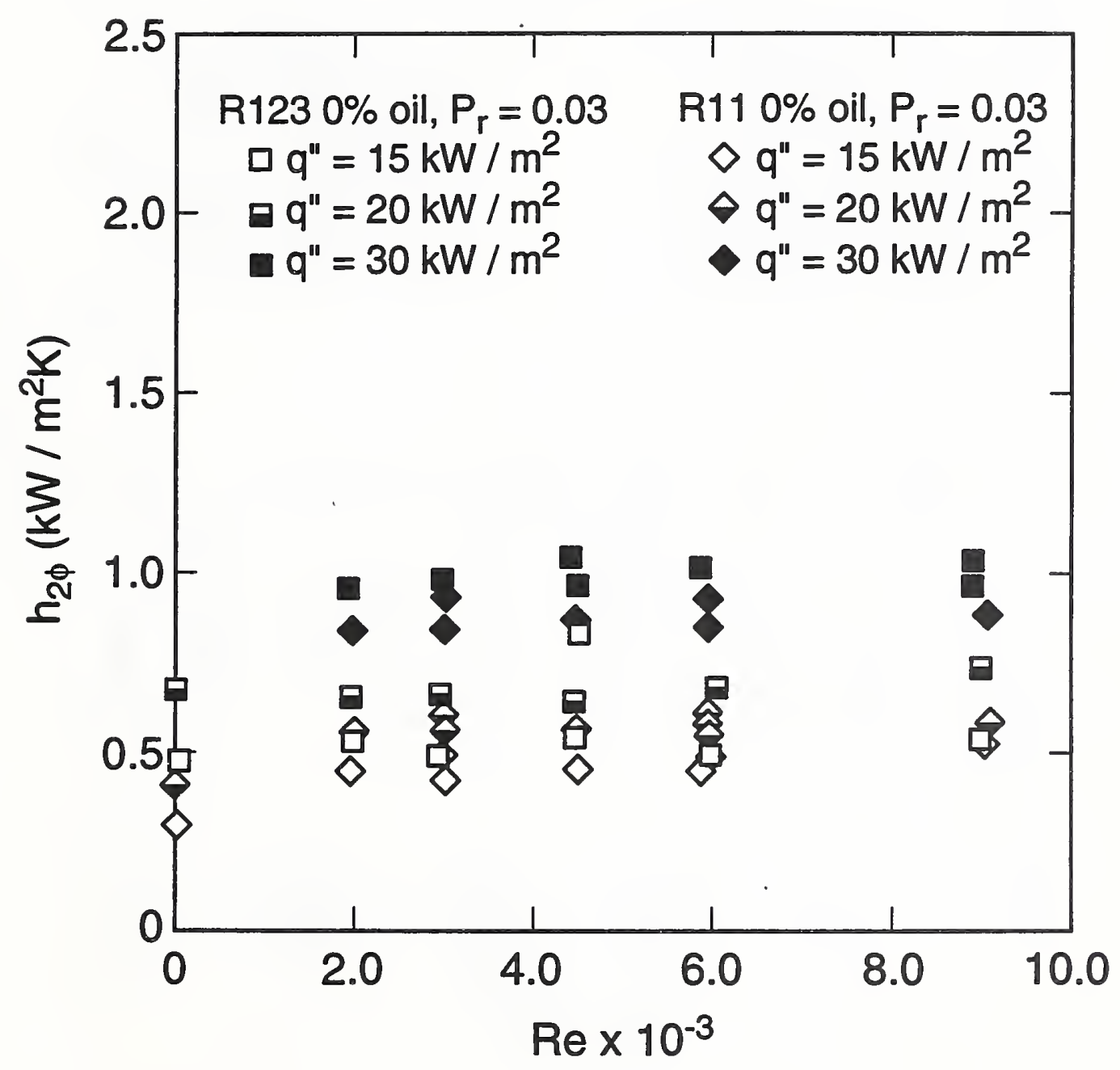

Fig. 5 Two-phase heat transfer coefficient measurements for pure R11 and pure R123 at $P_{r}=0.03$ 


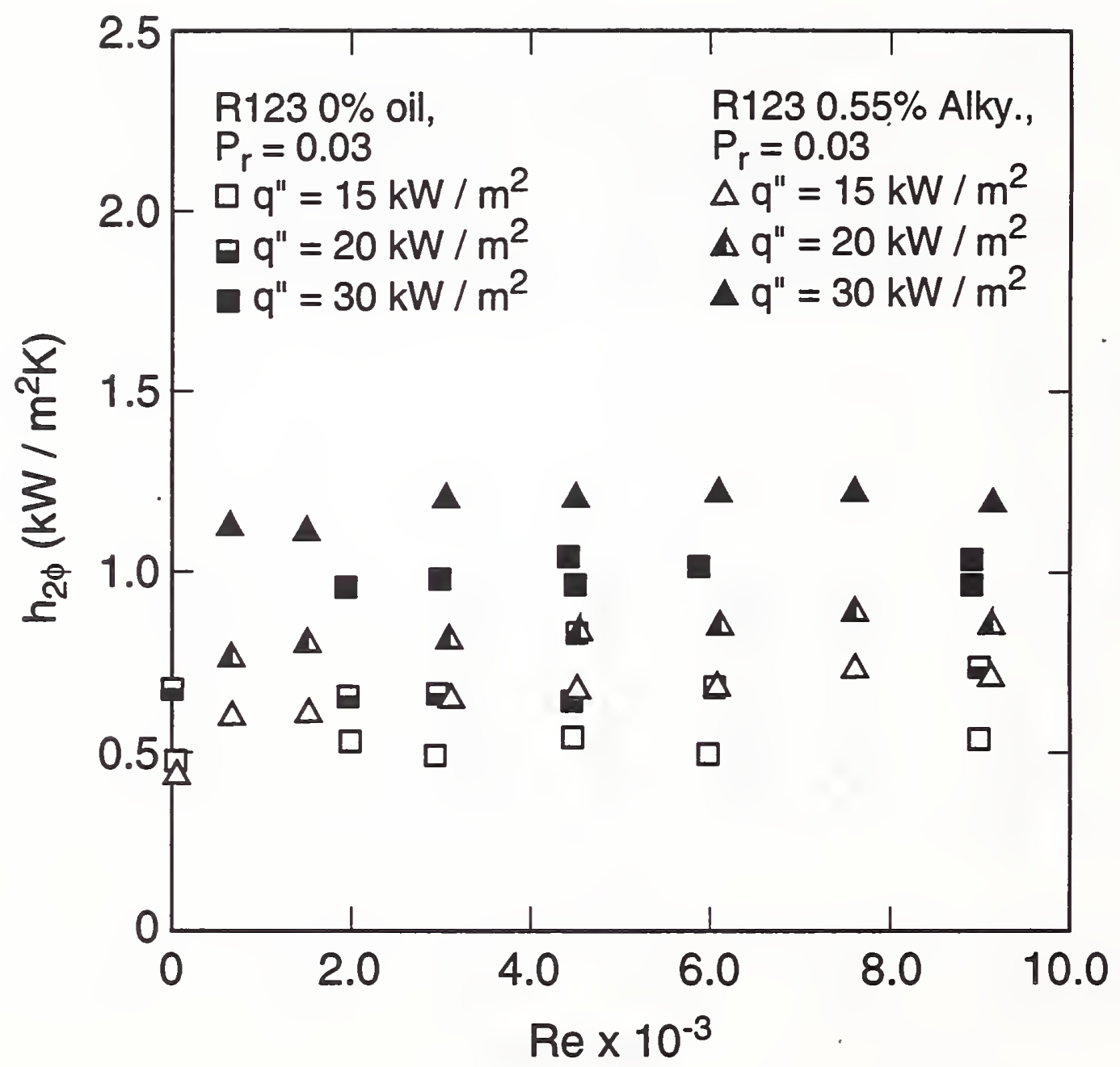

Fig. 6 Two-phase heat transfer coefficient measurements for R123/0.5\% alkylbenzene mixture and pure R123 at $\mathrm{P}_{\mathrm{r}}=0.03$ 


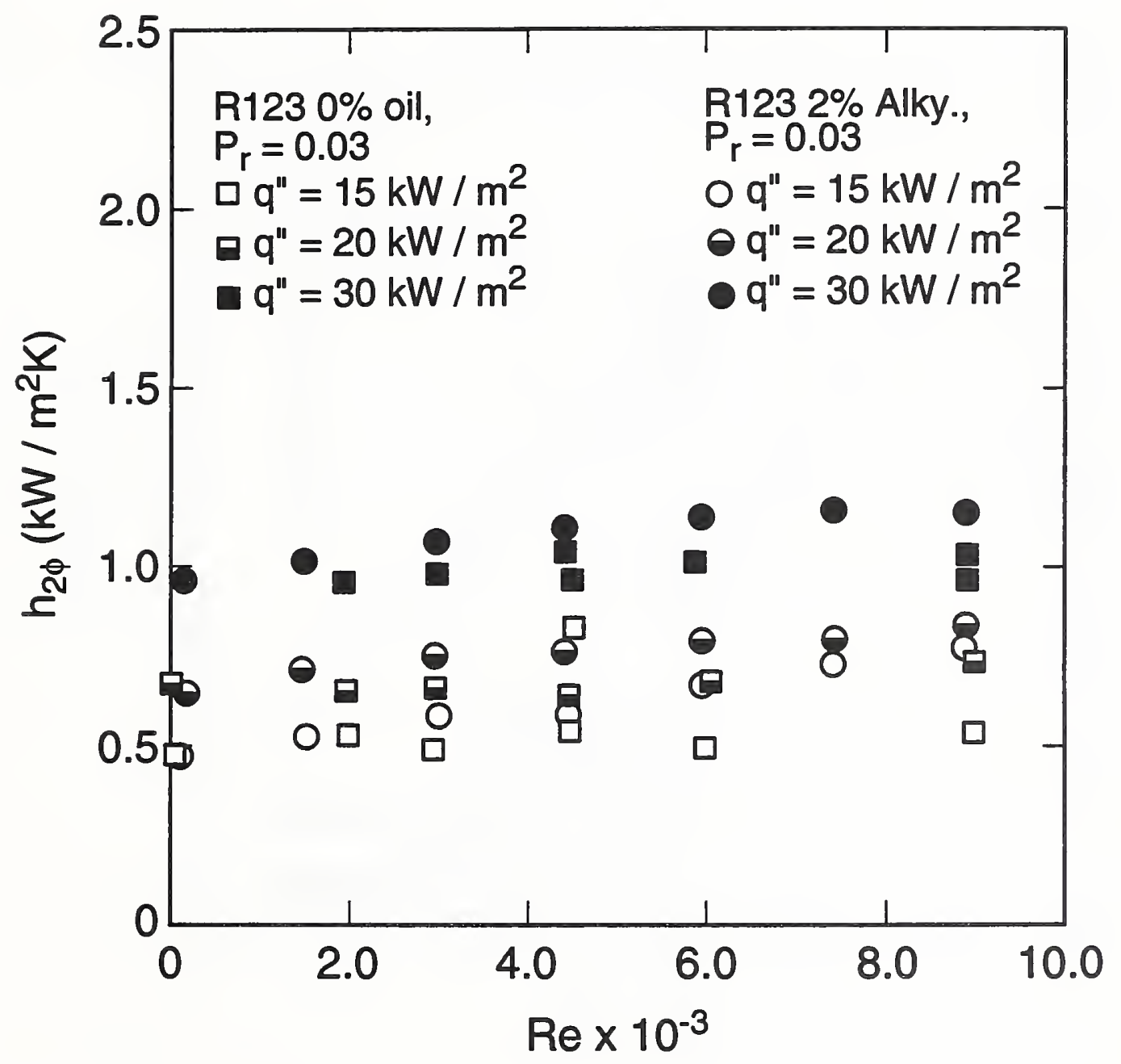

Fig. 7 Two-phase heat transfer coefficient measurements for R123/2\% alkylbenzene mixture and pure $\mathrm{R} 123$ at $\mathrm{P}_{\mathrm{r}}=0.03$ 


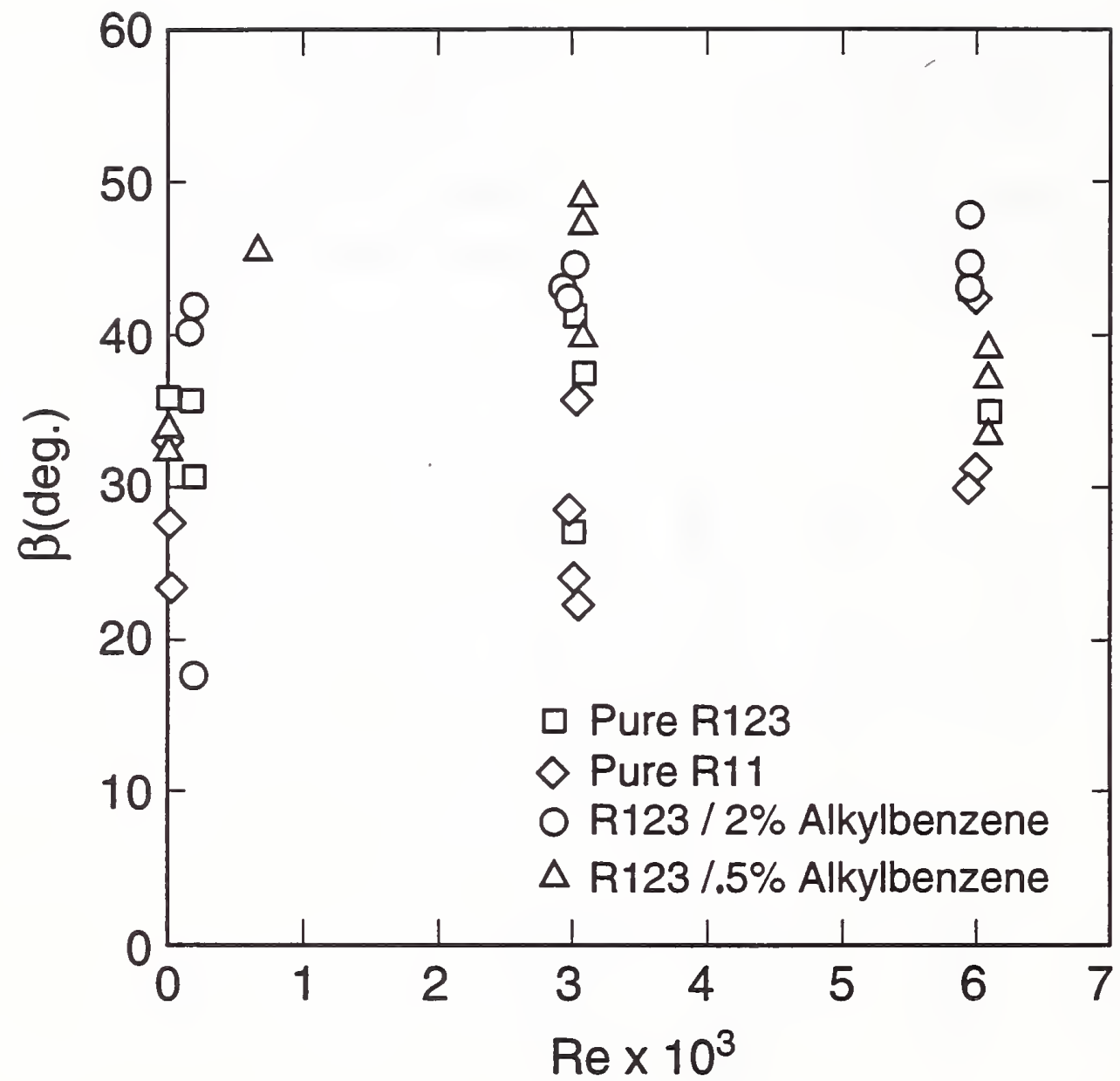

Fig. 8 Measured contact angle for R11, R123 and R123 and alkylbenzene 


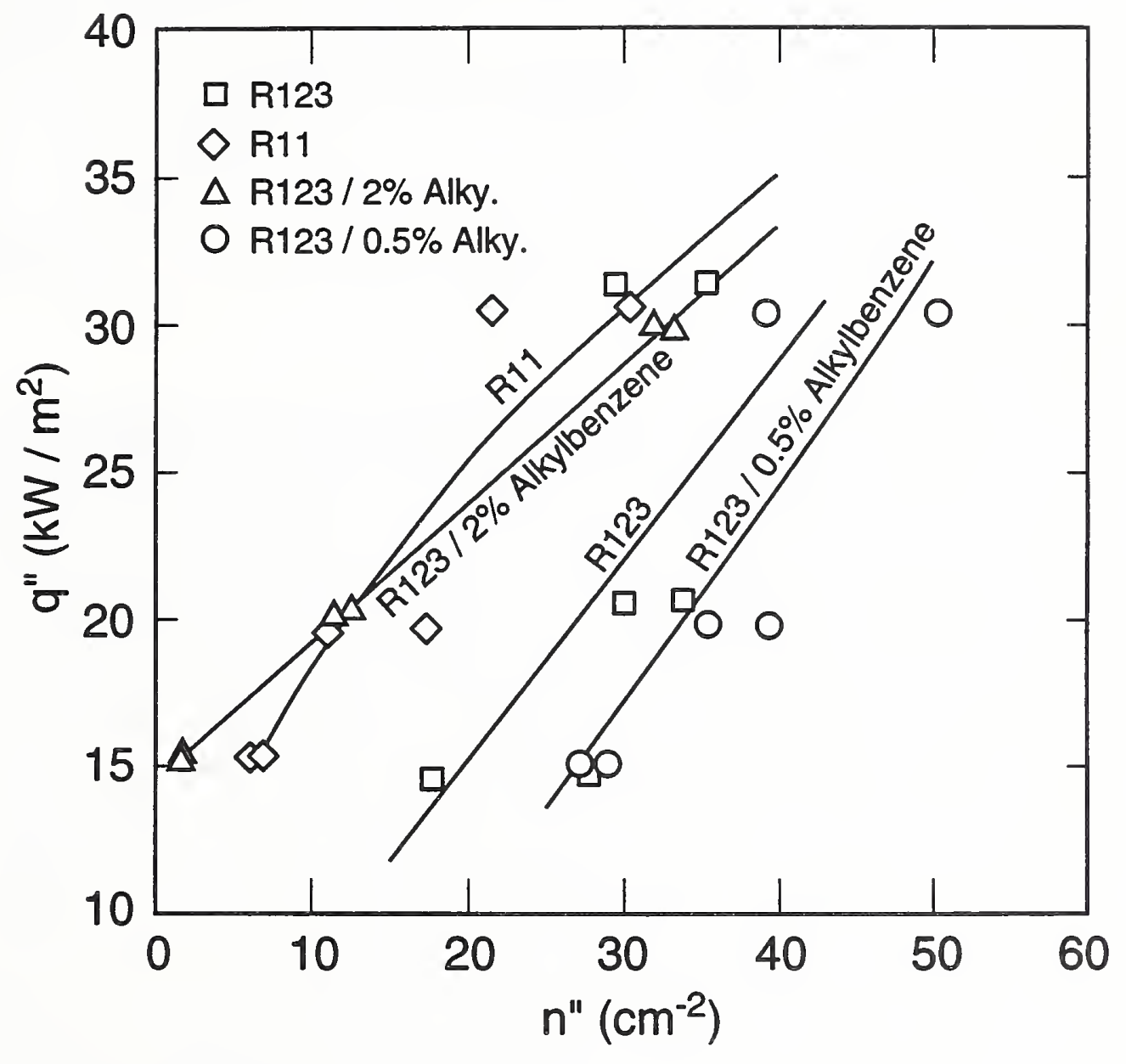

Fig. 9 Heat flux dependency on the nucleation site density for R11, R123 and R123 and alkylbenzene 


\begin{tabular}{|c|c|c|}
\hline \multirow{3}{*}{$\begin{array}{l}\text { NIST-114A } \\
\text { (REV. 3-80) }\end{array}$} & \multirow{3}{*}{$\begin{array}{l}\text { U.S. DEPARTMENT OF COMMERCE } \\
\text { NATIONAL INSTITUTE OF STANDARDS AND TECHNOLOGY } \\
\text { BIBLIOGRAPHIC DATA SHEET }\end{array}$} & $\begin{array}{l}\text { 1. PUELCATION OA REPOAT NULAEA } \\
\text { NIST IR } 4948\end{array}$ \\
\hline & & 2. PERFOAMING ORQARIZATION AEPOAT NUMBEER \\
\hline & & $\begin{array}{l}\text { 3. PUEUCATION DATE } \\
\text { OCTOBER } 1992\end{array}$ \\
\hline
\end{tabular}

\section{TIIEAMD SUBTTIE}

Simultaneous Visual and Calorimetric Measurements of R11, R123, and R123/Alkylbenzene Nucleate Flow Boiling

5. AUTHOR(S)

M.A. Kedzierski

6. PEAFOAMING ORCANEATION (IF JOINT OA OTMEA TMAN NIST, SEE LNSTRUCTIONS)

U.S. DEPARTMENT OF COMMERCE

MATIONAL INSTITUTE OF STANDARDS AND TECHNOLOQY

CATTHERSBURO, MD 20800

7. CONTRACT/GRANT NUMBER

Q. TYPE OF REPORT AND PERIOD COVERED

9. SPONSORINO ORCANIZATION MAME AND COLPLETE ADDRESS (STAET, CTT, STATE, ZIP)

U.S. Department of Energy

1000 Independence Avenue, SW

Washington, DC 20585

10. SUPPLEMENTANY NOTES

11. ABSTRACT (A 200-WOAD OA LESS FACTUAL SUMLAAY OF MOST SIGMIFICANT MMOAMATION. "F DOCUMENT INCLUDES SIONIFICANT BIBLOORAPHY OA

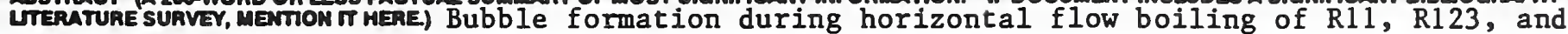
two R123/alkylbenzene mixtures was investigated both visually and calorimetrically. The only method by which knowledge of the fundamental mechanisms of boiling can be obtained is by the visualization of the ebullition process. The test fluid was pumped through the inside of a roughened, horizontal-quartz tube which was electrically heated with a metal strip. The refrigerant entered the test section slightly above the saturated state. Locally measured heat transfer coefficients were taken simultaneously with high speed motion picture images of the boiling process. Predictive equations from the literature yielded acceptable agreement with the measured bubble diameters and contact angles. The addition of lubricant to the Rl23 increased the size of the contact angle and reduced the size of the bubble. The measured bubble frequencies and site lensities did not agree very well with existing correlations. The addition of a small amount $(0.5 \%)$ of alkylbenzene to R123 increases the number of active nucleation sites by approximately 50,000 sites $/ \mathrm{m}^{2}$. The crease in the site density contributed to the enhancement of the heat transfer coefficient of the R123/0.5\% alkylbenzene mixture over that of the pure R123. Further increase in the amount of alkylbenzene to the Rl23 reduces the number of active sites to below that of pure R123 to approximately the value for that of Rll. Consequent 1 , the $0.5 \%$ concentration refrigerant/lubricant exhibited a heat transfer coefficient that was larger than that of the

2\% concentration mixture. Correspondingly, the lower heat transfer coefficient of Rll as companed

to that of R123 was partially due to the lower number of active boiling sites for R11. The

dependency of the measured two-phase heat transfer coefficient on the heat flux and Reynolds

number was investigated. Increases in both the heat flux and the Reynolds number caused increases in the heat transfer coefficient.

12. KEY WORDS (6 TO 12 ENTRIES; ALPHABETICAL ORDER; CAPTALIZE ONLY PROPER MAMES; AND SEPARATE KEY WORDS OV SEMICOLOHS) .

alkylbenzene; alternative refrigerants; boiling; bubble parameters; calorimetric; chemistry

dichlorotrifluoroethane; trichlorofluoromethane; visualization

$$
\text { Cbiblip trehoby }
$$

\section{AVALATITY}

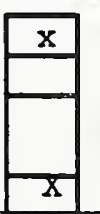

\section{UNLMITzD}

FOR OFFICLAL DISTRIEUTIOK. DO NOT RELEASE TO MATIOHAL TECHNICAL INFORMATION SERVCE (MTIS).

ORDER FMOM SUPERINTENDENT OF DOCUMEMTS, U.S. OOVERMLETT PAINTNG OFFCE, WASMINOTON, DC 20402

ORDEA FROM MATIONAL TECHNICAL INFORMATION SEAVCE (NTSS), SPRIMOFIED, VA 22161.

14. MULEER OF PAINTED PAQES

$$
54
$$

15. PAICE

$$
\mathrm{A} 0.4
$$




